\title{
Optimization of reaction parameters for the electrochemical oxidation of lidocaine with a Design of Experiments approach
}

\author{
Turan Gül $1^{1}$, Rainer Bischoff ${ }^{1}$, Hjalmar P. Permentier ${ }^{1,2^{*}}$ \\ ${ }^{1}$ Analytical Biochemistry, Groningen Research Institute of Pharmacy, University of Groningen, \\ Groningen, The Netherlands \\ ${ }^{2}$ Interfaculty Mass Spectrometry Center, University of Groningen, Groningen, The Netherlands \\ *Corresponding author: Hjalmar Permentier, Interfaculty Mass Spectrometry Center, University \\ of Groningen, Antonius Deusinglaan 1, 9713 AV Groningen, The Netherlands. Tel. +31-50-363- \\ 3262, Fax +31-50-363-7582, e-mail: h.p.permentier@ rug.nl
}

\begin{abstract}
Identification of potentially toxic oxidative drug metabolites is a crucial step in the development of new drugs. Electrochemical methods are useful to study oxidative drug metabolism, but are not widely used to synthesize metabolites for follow-up studies. Careful optimization of reaction parameters is important for scaling up the electrochemical synthesis of metabolites. In the present study, lidocaine was used as a drug compound in order to optimize electrochemical reaction parameters employing a design of experiments approach to improve the yield of $\mathrm{N}$-dealkylated lidocaine, a major in vivo metabolite. $\mathrm{pH}$ and electrode material were found to have a major effect on the final yield.
\end{abstract}

\section{Keywords}

- Design of Experiments (DOE)

- Drug metabolism

- Electrochemical synthesis

- Lidocaine

- N-dealkylation 


\section{Introduction}

The development of new drugs is a costly and time-consuming process. The detection and evaluation of possibly toxic oxidative drug metabolites at the early stages of drug discovery and development is therefore quite important [1-3]. Drug metabolism is initially studied in in vivo and in vitro experimental models, for example in human or animal liver microsomes $[4,5]$. However, these methods are not adequate to produce metabolites in sufficiently large quantities for follow-up studies [6]. In order to characterize the structure and study the toxicology of metabolites, it is necessary to have quantities in excess of $1 \mathrm{mg}[7,8]$. While organic synthesis is the standard approach, an emerging technique to produce oxidative metabolites is electrochemistry (EC), which can be combined with mass spectrometry (EC-MS) for product monitoring to optimize the conditions of metabolite synthesis $[9,10]$.

The local anesthetic lidocaine (Figure 1) has been used as a model compound for the study of oxidative metabolism by electrochemistry. The in vivo reactions, catalyzed by enzymes of the cytochrome $\mathrm{P} 450$ family, are $\mathrm{N}$-dealkylation and $\mathrm{N}$-oxidation of the tertiary amine, aromatic hydroxylation at the 3 and 4 positions and benzylic hydroxylation (Figure 1) [11-14]. Previously, our group reproduced most of these reactions by various electrochemical approaches. Jurva et al. [1] showed that direct electrochemical oxidation results in $\mathrm{N}$-dealkylation of lidocaine. NouriNigjeh et al. [15] showed further that indirect oxidation of lidocaine by electrochemically generated reactive oxygen species leads to N-oxide formation. Moreover, aromatic hydroxylations were observed at high potentials (3 V or more) in acetonitrile/water (99:1) containing 0.1 M tetrabutylammonium perchlorate as background electrolyte [16]. In addition, Nouri-Nigjeh et al. [16] showed that using square-wave potential pulses with long cycle times of around $1 \mathrm{~s}$ led to formation of the 4-hydroxylation product, but that short cycle times of $10 \mathrm{~ms}$ or less resulted in N-dealkylation. Although various electrochemical methods have been shown to produce different lidocaine metabolites, they were not optimized with respect to yield and reproducibility. Optimizing electrochemical synthetic methods is a multi-parameter problem with several interconnected factors affecting selectivity and yield. Electrochemical reaction parameters include substrate concentration, solvent, supporting electrolyte, $\mathrm{pH}$, temperature, oxidation potential, potential cycle times, electrode material, flow rate (for flow-through cells) or reaction time (for batch cells) and cell dimensions. A better understanding of the effects of the reaction conditions is thus needed prior to scaling the synthesis up. 
Optimization of EC parameters has thus far mostly been done using on-line EC-MS with commercially available flow-through cells [5,10,17-26]. In these systems, drug molecules are prepared in solvents of different compositions at different $\mathrm{pH}$ values, and these samples are pumped through a flow-through cell at various flow rates. A potential ramp may be applied over a desired range, and the electroactive species monitored by mass spectrometry and identified from the recorded mass voltammograms. While convenient with respect to selecting the optimal potential, this approach is time-consuming when it comes to parameters such as solvent, $\mathrm{pH}$ and electrode material and notably for assessing interdependent parameters. In addition, on-line ECMS limits the range of parameters, such as solvent, $\mathrm{pH}$ and electrolytes, since a compromise between MS and EC conditions must be found. The above-mentioned problems can be avoided by working off-line so that EC parameters can be optimized independent of the MS conditions [15,27-32].

In the present study, we used a multi-parametric optimization approach to increase yield and selectivity of electrochemical drug metabolite synthesis based on a Design of Experiments (DOE) strategy. A set of experiments was planned to obtain information about inter-parameter correlations and interactions from a limited number of experiments [33]. Lidocaine was used as model compound focusing on optimizing the yield of the N-dealkylation product. Our data show that reaction parameters such as $\mathrm{pH}$ and electrode material have a major effect on the final yield.

\section{Experimental Procedures}

\subsection{Reagents}

Lidocaine (L7757), monoethylglycinexylidide (MEGX, SML0087, the N-dealkylated form of lidocaine) and ammonium hydroxide $\left(\mathrm{NH}_{4} \mathrm{OH}, 221228\right)$ were purchased from Sigma-Aldrich. Formic acid (HCOOH, 94318) and acetaminophen (00370) were purchased from Fluka and ultrapure HPLC grade acetonitrile (ACN, 01203502) was purchased from Biosolve. Trifluoroacetic acid (TFA, 289084) was purchased from Thermo Fisher, and sulfuric acid $\left(\mathrm{H}_{2} \mathrm{SO}_{4}, 100731100\right)$ from Merck Millipore. Ultrapure water was obtained from a Milli-Q Advantage A10 Water Purification system (Millipore Corp., Billerica, MA, USA). 


\subsection{Electrochemical measurements}

All electrochemical measurements were performed with an Antec ROXY potentiostat (Antec Leyden, Zoeterwoude, The Netherlands) controlled by the Antec Dialogue software. Electrochemical reactions were performed in a one-compartment three-electrode cell in which the working electrodes were gold (MF-2014, $1.6 \mathrm{~mm}$ diameter, Bioanalytical System (BASi), West Lafayette, IN, USA), platinum (MF-2013, 1.6 mm diameter, BASi) or glassy carbon (GC) (MF2012, $3.0 \mathrm{~mm}$ diameter, BASi) disk electrodes and the auxiliary electrode a platinum wire (MW4130, BASi). Potentials were measured against a silver wire pseudo-reference electrode (MF2017, $\mathrm{BASi}$ ) to avoid possible chloride contamination from the traditional $\mathrm{Ag} / \mathrm{AgCl}$ reference electrode during electrochemical oxidations. All electrochemical experiments were performed at ambient temperature, and for deaeration argon gas was bubbled at $20 \mathrm{~mL} / \mathrm{min}$ via a sparge tube (MW-4145, BASi). Working electrodes surfaces were polished with a lapping sheet (Micromesh grade 3200 ) with a $0.05 \mu \mathrm{m}$ alumina slurry, followed by sonication in deionized water, ethanol and water for 1 min each. After mechanical polishing, the electrode surface was washed with ethanol and dried with nitrogen.

For acidic ( $\mathrm{pH}$ 3) sample conditions, $10 \mu \mathrm{M}$ lidocaine solutions were prepared in $\mathrm{ACN} / \mathrm{H}_{2} \mathrm{O}$ /formic acid (90/9.45/0.55), and $1000 \mu \mathrm{M}$ lidocaine solutions in $\mathrm{ACN} / \mathrm{H}_{2} \mathrm{O} /$ formic acid (90/8/2). For basic ( $\mathrm{pH}$ 12) conditions, $10 \mu \mathrm{M}$ and $1000 \mu \mathrm{M}$ lidocaine samples were prepared in $\mathrm{ACN} / \mathrm{NH}_{4} \mathrm{OH}(90 / 10)$. For $\mathrm{pH} 8$ and $\mathrm{pH} 10$ conditions, $10 \mu \mathrm{M}$ lidocaine samples were prepared in $\mathrm{ACN} / \mathrm{H}_{2} \mathrm{O} / \mathrm{NH}_{4} \mathrm{OH}(90 / 9.992 / 0.008)$ and $\mathrm{ACN} / \mathrm{H}_{2} \mathrm{O} / \mathrm{NH}_{4} \mathrm{OH}(90 / 8 / 2)$, respectively. Unless mentioned otherwise, $1 \mathrm{~mL}$ solutions of lidocaine were oxidized at various conditions according to the DOE experimental plan. After electrochemical oxidation for $30 \mathrm{~min}$, samples were diluted with water containing $100 \mu \mathrm{M}$ acetaminophen as internal standard (IS). For HPLC column compatibility, the basic sample ( $\mathrm{pH} 12$ ) was acidified to $\mathrm{pH} 3-4$ with $10 \%$ formic acid in water. The final composition of the samples contained $1 \mu \mathrm{M}$ lidocaine (based on the initial concentration) and $10 \mu \mathrm{M}$ acetaminophen for LC-MS analysis.

\subsection{Experimental Design}

The MODDE v.9.1.1.0 software (MKS Umetrics AB, Stortorget, Sweden) was used to produce a D-optimal design in order to optimize the electrochemical reaction parameters. The D-optimal design (determinant) is used for optimization problems that require coverage of a broad range of 
parameters with a minimal the number of experiments while gathering a maximum amount of information [33]. For the lidocaine metabolite production, a two-step optimization strategy was pursued where the second step employed a full factorial design instead of a D-optimal design (Tables 1 and 2).

\subsection{LC-MS analysis}

LC-MS analyses were carried out on an LC-Packings Ultimate Plus HPLC system (LC-Packings, Amsterdam, the Netherlands) coupled to a Thermo Finnigan TSQ Quantum AM triple quadrupole mass spectrometer with an ESI interface in the positive mode (Thermo Finnigan, San José, CA). The MS parameters for the TSQ Quantum AM were as follows: spray voltage $4000 \mathrm{~V}$, sheath gas pressure 40 , auxiliary gas pressure 20 , capillary temperature $350{ }^{\circ} \mathrm{C}$, tube lens offset $90 \mathrm{~V}$, skimmer offset $-0 \mathrm{~V}$, with scans between $\mathrm{m} / \mathrm{z}$ 100-300 (scan time $1 \mathrm{~s}$, Q1 peak width 0.70 amu FWHM). For selected reaction monitoring (SRM), 3 transitions were selected for lidocaine and its metabolites (lidocaine: 235/86, N-dealkylation product: 207/58, aromatic hydroxylation products: 251/86). For the acetaminophen IS the transition 152/110 was selected. All SRM measurements were performed with a dwell time of $100 \mathrm{~ms}$ each and Q1 and Q3 peak widths of 0.70 amu FWHM.

LC separations were performed with a $\mathrm{C}_{18}$ reversed-phase column (GraceSmart RP $185 \mu \mathrm{m}$, $2.1 \times 150 \mathrm{~mm}$; Grace Davison, Lokeren, Belgium) at a flow rate of $250 \mu \mathrm{L} / \mathrm{min}$. Solvent A was $\mathrm{H}_{2} \mathrm{O}$ with $0.1 \%$ formic acid, while solvent $\mathrm{B}$ was $\mathrm{ACN}$ with $0.1 \%$ formic acid. $20 \mu \mathrm{L}$ of the diluted oxidation product mixture were injected and a linear gradient was applied from 5 to $50 \%$ B over $10 \mathrm{~min}$, followed by an instant increase to $95 \% \mathrm{~B}$, which was held for $2 \mathrm{~min}$. The column was re-equilibrated at $5 \% \mathrm{~A}$ for $4 \mathrm{~min}$. Acetaminophen IS was used to normalize the peak areas of lidocaine and its oxidation products, resulting in the normalized product yield shown in Figures 1 and 2. Normalized product yields obtained for experiments using the GC electrode were additionally corrected for its larger surface area by dividing results by a factor of 3.5 .

\section{Results and Discussion}

\subsection{Optimization of EC parameters}

Based on literature examples, the most important EC parameters for the electrochemical synthesis of drug metabolites are $\mathrm{pH}$, substrate concentration, potential and electrode material [5,17-20]. In 
order to investigate the effect of these parameters on the synthesis of $\mathrm{N}$-dealkylated lidocaine systematically, a two-step optimization strategy was pursued, starting from a broad range of parameter levels. As mentioned in the Experimental Design section a D-optimal design was used to minimize the number of experiments while providing coverage of a broad parameter space. The LC-MS peak area of the N-dealkylation product was taken as output response. Other metabolites, namely the $\mathrm{N}$-oxide and aromatic hydroxylation products, were also monitored but were either absent (hydroxylations) or obtained in low and irreproducible yields (N-oxide). Three continuous range factors, $\mathrm{pH}(3-12)$, concentration $(10-1000 \mu \mathrm{M})$, and potential $(0.75-1.50 \mathrm{~V})$ were defined as well as one a discrete factor, the electrode material (Au, Pt or glassy carbon). The software produced a set of 23 conditions, including three replicates of one randomly selected condition. LC-MS results of this first round of optimization are shown in Figure 2 revealing that by far the highest amount of N-dealkylation product was obtained in experiment 12 corresponding to a $\mathrm{pH}$ of 12 and a potential of $1.5 \mathrm{~V}$ in combination with a low starting concentration $(10 \mu \mathrm{M})$ and a glassy carbon electrode. Surprisingly, in most experiments where $1000 \mu \mathrm{M}$ starting concentrations were used the $\mathrm{N}$-dealkylation product was obtained in relatively low yield or was even absent. Acidic conditions clearly produced lower yields, as evidenced by comparing experiments 11 and 12, which only differ in $\mathrm{pH}$ ( 3 and 12, respectively). This is interesting, since a large majority of electrochemical drug oxidation experiments reported in the literature were performed at acidic $\mathrm{pH}$.

The first-step optimization results encouraged us to investigate the effect of $\mathrm{pH}$ and potential on $\mathrm{N}$-dealkylation of lidocaine in more detail as these appeared to be the most important parameters. In the second-step optimization, $10 \mu \mathrm{M}$ lidocaine and the GC electrode were used throughout and narrower ranges were defined for the $\mathrm{pH}(8,10$ and 12$)$ and the oxidation potential $(0.75,1.00$, 1.25 and $1.50 \mathrm{~V}$ ). A full set of fifteen parameter combinations was generated, including three replicates for one condition. The LC-MS results confirmed that high $\mathrm{pH}$ values and high oxidation potentials produced the highest amount of N-dealkylation product (Figure 3). As expected, the differences in yields were smaller, and no significant increase was observed between 1.25 and $1.5 \mathrm{~V}$.

Supporting electrolytes are required for conductivity, but their effect on the synthesis was not considered during optimization of the EC parameters. A control experiment was thus performed 

explained by the difference in supporting electrolyte type and concentration. For this purpose, 10 $\mu \mathrm{M}$ lidocaine was prepared at $\mathrm{pH} 3$ in $90 \% \mathrm{ACN}$ and $10 \% \mathrm{H}_{2} \mathrm{O}$ (containing $10 \mathrm{mM} \mathrm{NaCl}$ and $1 \%$ FA) and at pH 12 in $90 \% \mathrm{ACN}$ and $10 \%$ (aq.) $\mathrm{NH}_{4} \mathrm{OH}$ (containing $10 \mathrm{mM} \mathrm{NaCl}$ ). The samples were oxidized at $1.5 \mathrm{~V}$ using the glassy carbon electrode. LC-MS results of samples containing additional supporting electrolyte showed almost the same relative yield of the N-dealkylation product as samples without additional $\mathrm{NaCl}$, at both $\mathrm{pH} 3$ and 12. These results indicated that the use of additional electrolyte does not affect synthesis yield.

Reproducibility of metabolite yield is rarely reported in studies of electrochemical drug oxidation, but is crucial for reliable optimization of conditions and further scale up. In our study one randomly chosen condition was measured in triplicate in both the first and second round of optimizations. In addition, the entire second optimization was performed in duplicate. As indicated in Figures 2 and 3, the yields were reproducible to within +/- 18\%.

\section{2. pH effect on $\mathbf{N}$-dealkylation}

The results of the optimization experiment can be rationalized by examining the N-dealkylation mechanism [15]. Salamone et al. proposed that hydrogen abstraction from the aliphatic C-H group adjacent to a basic group can be tuned depending on the strength of the added acid [34]. If lidocaine $\mathrm{N}$-dealkylation is indeed initiated in this way, then acidic conditions should prevent $\mathrm{N}$ dealkylation, whereas basic conditions should favor this reaction, as observed in our study. To investigate this further, we performed additional experiments at $\mathrm{pH}$ values between 0.5 and 3.0. $10 \mu \mathrm{M}$ lidocaine solutions were prepared in $\mathrm{ACN} / \mathrm{H}_{2} \mathrm{O} /$ formic acid (90/9.45/0.55; $\mathrm{pH} 3.0$ ), in $\mathrm{ACN} / \mathrm{H}_{2} \mathrm{O} / \mathrm{TFA}(90 / 9.45 / 0.55 ; \mathrm{pH} 1.5)$, in $\mathrm{ACN} / \mathrm{H}_{2} \mathrm{O} / \mathrm{TFA}(90 / 5 / 5 ; \mathrm{pH} 0.5)$ and oxidized for 30 min in a batch cell at $1.5 \mathrm{~V}$ using a GC working electrode. The LC-MS results showed that Ndealkylation is completely blocked at $\mathrm{pH} 0.5$ while there is still some $\mathrm{N}$-dealkylation at $\mathrm{pH} 1.5$ (Figure $4 \mathrm{a}-\mathrm{d}$ ). That this effect is not specific for TFA was confirmed by electrochemical oxidation of lidocaine in $\mathrm{ACN} / \mathrm{H}_{2} \mathrm{O} / \mathrm{H}_{2} \mathrm{SO}_{4}(90 / 7.5 / 2.5 ; \mathrm{pH} 0.5)$ showing that there was no Ndealkylation (Figure 4e). Strongly basic and acidic conditions have not previously been considered for drug metabolite synthesis by EC but are important to include in the parameter range for DOE optimization approaches. 


\section{Conclusions}

The EC synthesis of the N-dealkylation product of lidocaine was optimized using a two-step DOE approach to efficiently cover a wide range of parameters. LC-MS in the selected reaction monitoring (SRM) mode was used to follow product formation in a sensitive and selective manner. We found that high $\mathrm{pH}$ and a high potential in combination with relatively low lidocaine concentrations and a glassy carbon electrode are most favorable for the synthesis of the $\mathrm{N}$ dealkylation product. The relative yields under the most favorable conditions are still in the low percentage range but this is likely due to the small surface area of the electrode.

High $\mathrm{pH}$ values, which are favorable for $\mathrm{N}$-dealkylation, are not commonly used in the field of EC drug oxidation. The results can, however, be reconciled with the mechanistic view that abstraction of a hydrogen atom from the $\mathrm{CH}$ group adjacent to the tertiary amine is critical to initiate the N-dealkylation reaction [34]. This proposed mechanism was confirmed by blocking the reaction completely at $\mathrm{pH} 0.5$, well below the $\mathrm{pH}$ range initially used. Our data show that a multistep DOE strategy is an efficient approach to optimizing the many interacting parameters in EC-driven drug metabolite synthesis reactions covering a broad parameter range.

\section{Acknowledgements}

The authors thank Dutch Technology Foundation (STW, project 11957) for providing financial support. We thank Peter Horvatovich for fruitful discussions on DOE and Massimo Bietti for pointing out the $\mathrm{pH}$ effect on N-dealkylation reactions (EU-COST action CM1201).

\section{References}

[1] U. Jurva, H.V. Wikström, A.P. Bruins, In vitro mimicry of metabolic oxidation reactions by electrochemistry/mass spectrometry, Rapid Commun. Mass Spectrom. 14 (2000) 529.

[2] A. Baumann, U. Karst, Online electrochemistry/mass spectrometry in drug metabolism studies: principles and applications, Expert Opin. Drug Metab. Toxicol. 6 (2010) 715.

[3] W. Lohmann, A. Baumann, U. Karst, Electrochemistry and LC - MS for Metabolite Generation and Identification: Tools, Technologies and Trends, LC-GC Eur. (2010) 1.

[4] E.F.A. Brandon, C.D. Raap, I. Meijerman, J.H. Beijnen, J.H.M. Schellens, An update on in vitro test methods in human hepatic drug biotransformation research: pros and cons, Toxicol. Appl. Pharmacol. 189 (2003) 233. 
[5] A. Baumann, W. Lohmann, B. Schubert, H. Oberacher, U. Karst, Metabolic studies of tetrazepam based on electrochemical simulation in comparison to in vivo and in vitro methods, J. Chromatogr. A. 1216 (2009) 3192.

[6] T. Johansson, U. Jurva, G. Grönberg, L. Weidolf, C. Masimirembwa, G. Gro, Novel metabolites of amodiaquine formed by CYP1A1 and CYP1B1: structure elucidation using electrochemistry, mass spectrometry, and NMR, Drug Metab. Dispos. 37 (2009) 571.

[7] R. Stalder, G.P. Roth, Preparative Microfluidic Electrosynthesis of Drug Metabolites, ACS Med. Chem. Lett. 4 (2013) 1119.

[8] S. Khera, N. Hu, Generation of statin drug metabolites through electrochemical and enzymatic oxidations, Anal. Bioanal. Chem. 405 (2013) 6009.

[9] F. Zhou, G.J. Van Berkel, Electrochemistry Combined Online with Electrospray Mass Spectrometry, Anal. Chem. 67 (1995) 3643.

[10] T. Johansson, L. Weidolf, U. Jurva, Mimicry of phase I drug metabolism - novel methods for metabolite characterization and synthesis, Rapid Commun. Mass Spectrom. 21 (2007) 2323.

[11] L.E. Mather, J. Thomas, Metabolism of lidocaine in man, Life Sci. 11 (1972) 915.

[12] J. Thomas, P. Meffin, Aromatic hydroxylation of lidocaine and mepivacaine in rats and humans, J. Med. Chem. 15 (1972) 1046.

[13] Y. Oda, S. Imaoka, Y. Nakahira, A. Asada, M. Fujimori, S. Fujita, Metabolism of lidocaine by purified rat liver microsomal cytochrome P-450 isozymes, Biochem. Pharmacol. 38 (1989) 4439.

[14] R. Kawai, S. Fujita, T. Suzuki, A new lidocaine metabolite, omega-diethylamino-2hydroxymethyl-6-methylacetanilide, Drug Metab. Dispos. 14 (1986) 277.

[15] E. Nouri-Nigjeh, H.P. Permentier, R. Bischoff, A.P. Bruins, Lidocaine oxidation by electrogenerated reactive oxygen species in the light of oxidative drug metabolism, Anal. Chem. 82 (2010) 7625.

[16] E. Nouri-Nigjeh, H.P. Permentier, R. Bischoff, A.P. Bruins, Electrochemical oxidation by square-wave potential pulses in the imitation of oxidative drug metabolism, Anal. Chem. 83 (2011) 5519.

[17] W. Lohmann, U. Karst, Simulation of the detoxification of paracetamol using on-line electrochemistry/liquid chromatography/mass spectrometry, Anal. Bioanal. Chem. 386 (2006) 1701. 
[19] U. Jurva, H. V. Wikström, L. Weidolf, A.P. Bruins, Comparison between electrochemistry/mass spectrometry and cytochrome $\mathrm{P} 450$ catalyzed oxidation reactions, Rapid Commun. Mass Spectrom. 17 (2003) 800.

[20] W. Lohmann, U. Karst, Generation and identification of reactive metabolites by electrochemistry and immobilized enzymes coupled on-line to liquid chromatography/mass spectrometry, Anal. Chem. 79 (2007) 6831.

[21] X. Xu, W. Lu, R.B. Cole, On-line probe for fast electrochemistry/electrospray mass spectrometry. Investigation of polycyclic aromatic hydrocarbons, Anal. Chem. 68 (1996) 4244.

[22] K. Tahara, Y. Yano, K. Kanagawa, Y. Abe, J. Yamada, S. Iijima, Successful preparation of metabolite of troglitazone by in-flow electrochemical reaction on coulometric electrode, Chem. Pharm. Bull. 55 (2007) 1207.

[23] M. Regino, C. Weston, A. Brajter-Toth, Effect of mobile phase composition on the electrochemical cell conversion efficiency in electrochemistry/mass spectrometry, Anal. Chim. Acta 369 (1998) 253.

[24] H. Chen, Y. Zhang, A.E. Mutlib, M. Zhong, Application of on-line electrochemical derivatization coupled with high-performance liquid chromatography electrospray ionization mass spectrometry for detection and quantitation of (p-chlorophenyl)aniline in biological samples, Anal. Chem. 78 (2006) 2413.

[25] W. Lu, X. Xu, R.B. Cole, On-line linear sweep voltammetry-electrospray mass spectrometry, Anal. Chem. 69 (1997) 2478.

[26] M. Karady, O. Novák, A. Horna, M. Strnad, K. Doležal, High Performance Liquid Chromatography-Electrochemistry-Electrospray Ionization Mass Spectrometry (HPLC/EC/ESI-MS) for Detection and Characterization of Roscovitine Oxidation Products, Electroanalysis 23 (2011) 2898.

[27] S. Jahn, U. Karst, Electrochemistry coupled to (liquid chromatography/) mass spectrometry - Current state and future perspectives, J. Chromatogr. A. 1259 (2012) 16.

[28] H. Oberacher, F. Pitterl, R. Erb, S. Plattner, Mass spectrometric methods for monitoring redox processes in electrochemical cells, Mass Spectrom. Rev. 34 (2015) 64.

[29] T. Shono, T. Toda, N. Oshhino, Preparation of N-dealkylated Drug Metabolites by Electrochemical Simulation of Biotransformation, Drug Metab. Dispos. 9 (1981) 481. 
[30] J. Skopalová, J. Vacek, B. Papoušková, D. Jirovský, V. Maier, V. Ranc, Electrochemical oxidation of berberine and mass spectrometric identification of its oxidation products, Bioelectrochemistry 87 (2012) 15.

[31] R. Galvão de Lima, P.S. Bonato, R. Santana da Silva, Analysis of albendazole metabolites by electrospray LC-MS/MS as a probe to elucidate electro-oxidation mechanism of albendazole, J. Pharm. Biomed. Anal. 32 (2003) 337.

[32] F. Zhang, G. Dryhurst, Influence of glutathione on the oxidation chemistry of the catecholaminergic neurotransmitter dopamine, J. Electroanal. Chem. 398 (1995) 117.

[33] L. Erikson, E. Johansson, N. Kettaneh-Wold, C. Wikström, S. Wold, Design of Experiments: Principles and Applications, in: L. Eriksson (Ed.), MKS Umetrics AB, Umeå, 2008, p.4.

[34] M. Salamone, I. Giammarioli, M. Bietti, Tuning hydrogen atom abstraction from the aliphatic $\mathrm{C}-\mathrm{H}$ bonds of basic substrates by protonation. Control over selectivity by $\mathrm{C}-\mathrm{H}$ deactivation, Chem. Sci. 4 (2013) 3255. 
FIGURES<smiles>[R]c1cc([R])c(NC(=O)CN(CC)CC)c(C)c1[R3]</smiles>

$\mathbf{R}_{1}=\mathrm{CH}_{3}, \mathbf{R}_{2}=\mathrm{H}, \mathrm{R}_{3}=\mathrm{H} \quad$ lidocaine

$\mathbf{R}_{1}=\mathrm{CH}_{3}, \mathrm{R}_{2}=\mathrm{H}, \mathrm{R}_{3}=\mathrm{OH}$ 3-hydroxylidocaine<smiles>CCNCC(=O)Nc1c(C)cccc1C</smiles>

$\mathrm{N}$-dealkylation metabolite<smiles>CC[N+]([O-])(CC)CC(=O)Nc1c(C)cccc1C</smiles>

N-oxide metabolite

$\mathrm{R}_{1}=\mathrm{CH}_{2} \mathrm{OH}, \mathrm{R}_{2}=\mathrm{H}, \mathrm{R}_{3}=\mathrm{H}$ 2-hydroxymethyl lidocaine

Figure 1. Lidocaine and its major metabolites. 




Figure 2. LC-MS results of the first round of optimizations of the DOE design indicating the relative yields of the $\mathrm{N}$-dealkylation product of lidocaine under different experimental conditions (see Table 1 for details). The experimental design included three replicates (Exp 21-23) which

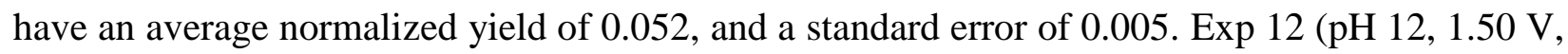
$\mathrm{GC}, 10 \mu \mathrm{M})$ gave by far the highest yield. 


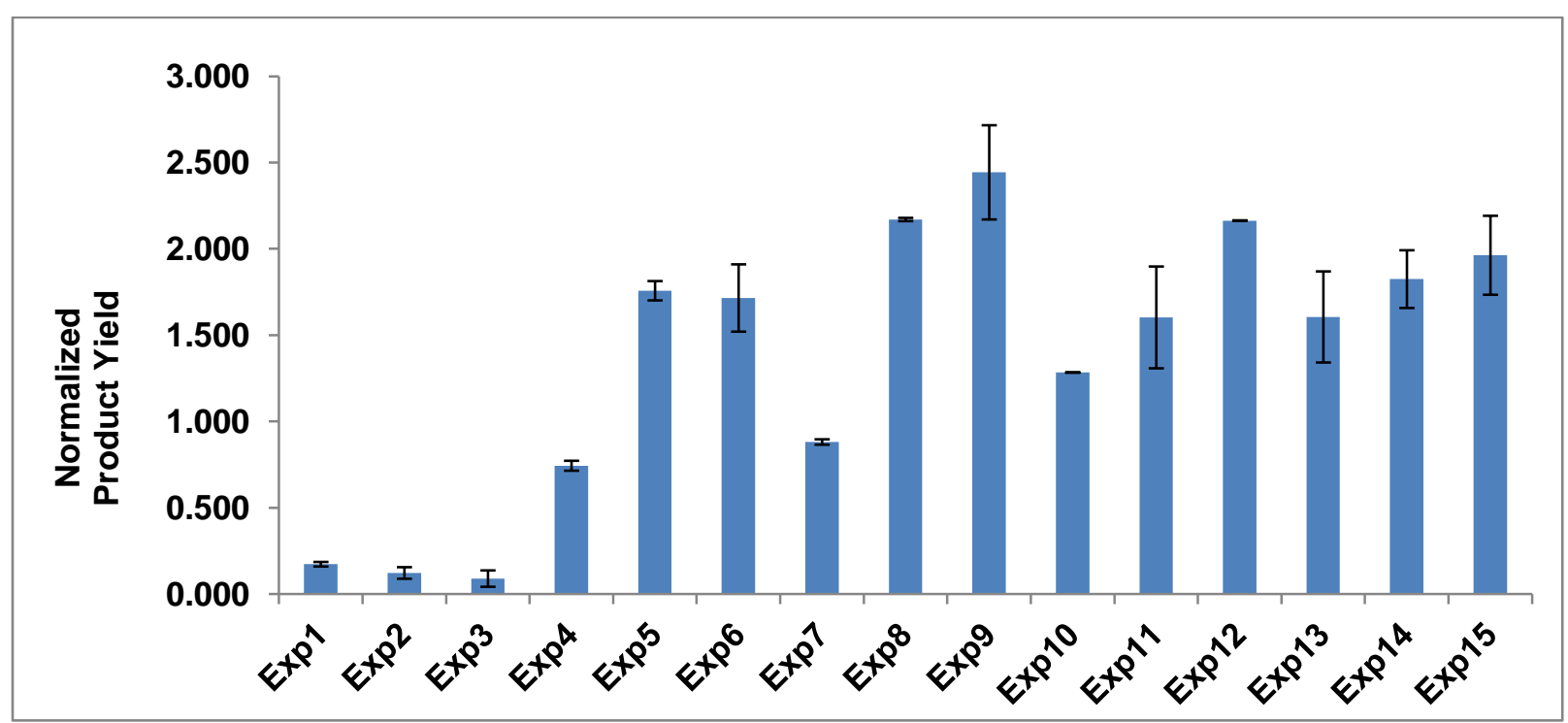

Figure 3. LC-MS results of the second round of optimizations (10 $\mu \mathrm{M}$ lidocaine, GC electrode) across a narrower range of parameter values (see Table 2 for details). All experiments were performed in duplicate and the error bars show the standard error. $\operatorname{Exp} 9(\mathrm{pH} \mathrm{12}, 1.25 \mathrm{~V})$ gave the highest N-dealkylation product yield. 


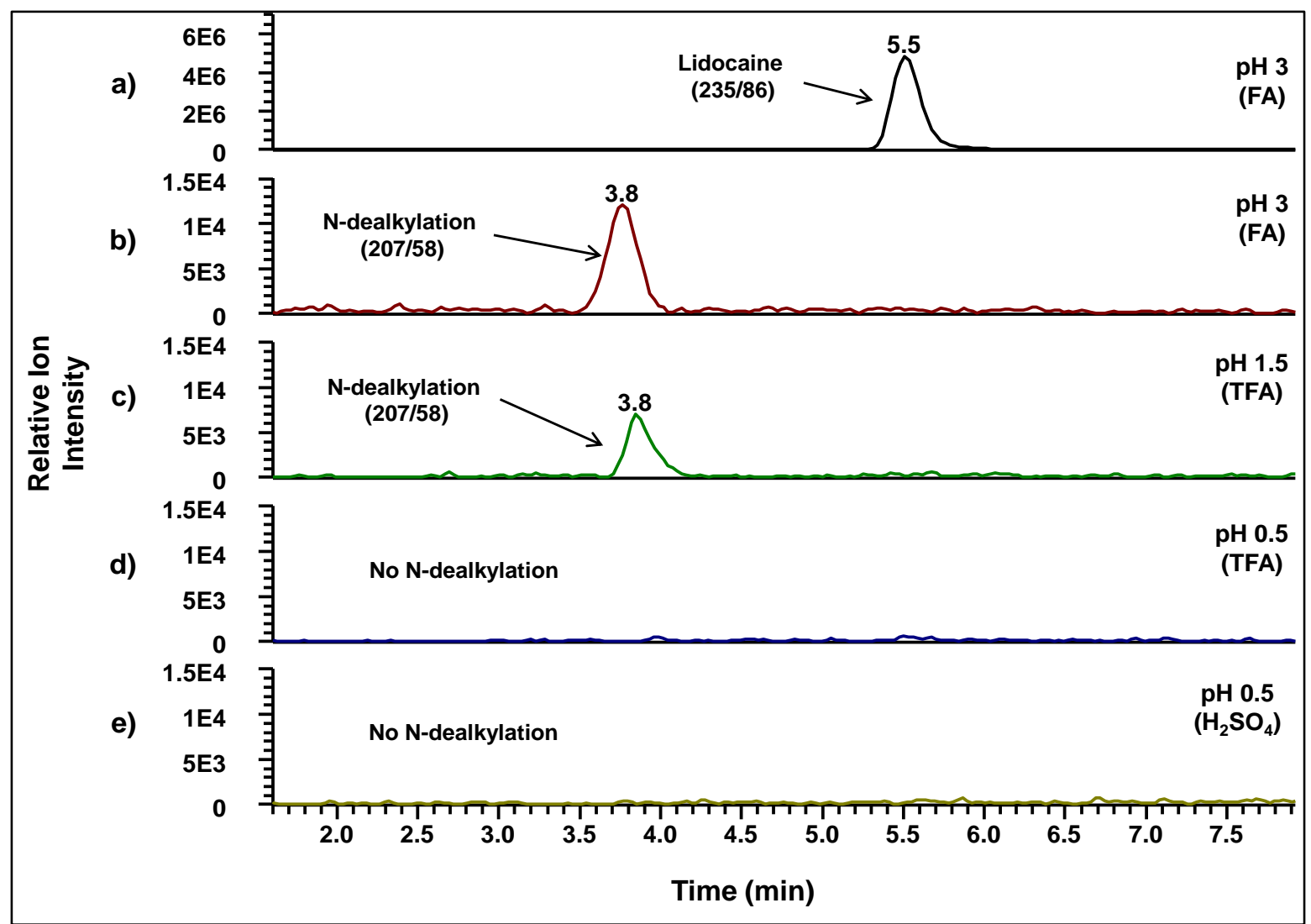

Figure 4. LC-MS in the SRM mode of lidocaine (235/86) at a) $\mathrm{pH} 3$ (FA) and of the Ndealkylation product of lidocaine (207/58) after EC oxidation for 30 min using a glassy carbon electrode and $1.5 \mathrm{~V}$; b) pH 3 (FA), c) pH 1.5 (TFA), d) pH 0.5 (TFA), and e) pH $0.5\left(\mathrm{H}_{2} \mathrm{SO}_{4}\right)$. At $\mathrm{pH} 0.5$ the $\mathrm{N}$-dealkylation product of lidocaine was below the detection limit. 
Table 1. Experimental plan for the first round of optimizations of the lidocaine N-dealkylation reaction conditions. The plan includes three replicates (Exp 21-23). The D-optimal experimental design with a minimal number of experiments implies that only the extreme values of each parameter range were investigated.

\begin{tabular}{|c|c|c|c|c|c|}
\hline $\begin{array}{l}\text { Exp } \\
\text { Name }\end{array}$ & $\begin{array}{l}\text { Run } \\
\text { order }\end{array}$ & $\mathbf{p H}$ & $\begin{array}{c}c \\
(\mu \mathrm{mol} \\
\left.\mathrm{dm}^{-3}\right)\end{array}$ & Electrodes & $\begin{array}{l}\text { Potential } \\
\text { (E) }\end{array}$ \\
\hline Exp 1 & 23 & 3 & 10 & Carbon & 0.75 \\
\hline $\operatorname{Exp} 2$ & 10 & 3 & 1000 & Carbon & 0.75 \\
\hline Exp 3 & 15 & 12 & 1000 & Carbon & 0.75 \\
\hline Exp 4 & 12 & 3 & 10 & Pt & 0.75 \\
\hline Exp 5 & 5 & 12 & 10 & $\mathbf{P t}$ & 0.75 \\
\hline Exp 6 & 11 & 3 & 1000 & $\mathrm{Pt}$ & 0.75 \\
\hline $\operatorname{Exp} 7$ & 9 & 12 & 1000 & $\mathrm{Pt}$ & 0.75 \\
\hline Exp 8 & 14 & 3 & 10 & $\mathrm{Au}$ & 0.75 \\
\hline Exp 9 & 1 & 12 & 10 & $\mathrm{Au}$ & 0.75 \\
\hline Exp 10 & 16 & 3 & 1000 & $\mathrm{Au}$ & 0.75 \\
\hline Exp 11 & 19 & 3 & 10 & Carbon & 1.50 \\
\hline Exp 12 & 13 & 12 & 10 & Carbon & 1.50 \\
\hline Exp 13 & 6 & 3 & 1000 & Carbon & 1.50 \\
\hline Exp 14 & 7 & 3 & 10 & $\mathbf{P t}$ & 1.50 \\
\hline Exp 15 & 21 & 12 & 10 & $\mathbf{P t}$ & 1.50 \\
\hline Exp 16 & 3 & 3 & 1000 & $\mathbf{P t}$ & 1.50 \\
\hline Exp 17 & 17 & 12 & 1000 & $\mathbf{P t}$ & 1.50 \\
\hline Exp 18 & 8 & 3 & 10 & $\mathrm{Au}$ & 1.50 \\
\hline Exp 19 & 18 & 3 & 1000 & $\mathrm{Au}$ & 1.50 \\
\hline Exp 20 & 2 & 12 & 1000 & $\mathrm{Au}$ & 1.50 \\
\hline Exp 21 & 4 & 12 & 1000 & $\mathrm{Au}$ & 1.50 \\
\hline Exp 22 & 20 & 12 & 1000 & $\mathrm{Au}$ & 1.50 \\
\hline Exp 23 & 22 & 12 & 1000 & $\mathrm{Au}$ & 1.50 \\
\hline
\end{tabular}


Table 2. Experimental plan of the second round of optimizations. The experiments were performed in duplicate and cover the full set of parameter combinations $(\mathrm{pH} 8,10,12$, and potential $0.75,1.00,1.25$ and 1.50 V) (including 3 replicates, Exp 13-15). $10 \mu \mathrm{M}$ lidocaine concentration and glassy carbon electrode were used for all experiments.

\begin{tabular}{|c|c|c|c|}
\hline $\begin{array}{c}\text { Exp } \\
\text { Name }\end{array}$ & $\begin{array}{c}\text { Run } \\
\text { Order }\end{array}$ & pH & $\begin{array}{c}\text { Potential } \\
(\text { E) }\end{array}$ \\
\hline Exp 1 & 13 & 8 & 0.75 \\
\hline Exp 2 & 12 & 10 & 0.75 \\
\hline Exp 3 & 15 & 12 & 0.75 \\
\hline Exp 4 & 9 & 8 & 1.00 \\
\hline Exp 5 & 6 & 10 & 1.00 \\
\hline Exp 6 & 10 & 12 & 1.00 \\
\hline Exp 7 & 2 & 8 & 1.25 \\
\hline Exp 8 & 5 & 10 & 1.25 \\
\hline Exp 9 & 14 & 12 & 1.25 \\
\hline Exp 10 & 1 & 8 & 1.50 \\
\hline Exp 11 & 3 & 10 & 1.50 \\
\hline Exp 12 & 4 & 12 & 1.50 \\
\hline Exp 13 & 8 & 10 & 1.00 \\
\hline Exp 14 & 7 & 10 & 1.00 \\
\hline Exp 15 & 11 & 10 & 1.00 \\
\hline
\end{tabular}

